\title{
Earth Block Construction in Nepal as Alternative to Reconstruction after the 2015 Gorkha Earthquake
}

\author{
Aayush Kasajoo, Ma Hongwang \\ Department of Civil Engineering, Shanghai Jiao Tong University, 200240, Shanghai, China \\ Corresponding author:akasajoo@sjtu.edu.cn
}

Received: Dec 25, 2017

Revised: Jan 17, 2018

Accepted: Jan 25, 2018

\begin{abstract}
On April 25, 2015, 7.8 magnitude earthquake occurred in Central Nepal with epicentre in Gorkha District at 11:56 NST (local time). A major aftershock of magnitude 7.3 on May 12, 2015 resulted in enhancement of damages. Almost 800,000 buildings were fully or partially damaged. This paper highlights the different types of buildings in Nepal and the damage patterns recorded from the earthquake. Different causes of failures are highlighted for different types of building including masonry, wooden, reinforced cement concrete etc. $44.2 \%$ of the buildings in Nepal are masonry type which in fact performed the worst during the earthquake. One of the main reason was the poor quality of bricks used in the buildings. Most of the masonry buildings in Nepal are located in the rural areas where the economic condition of people are not up to the level. Utilization of local resources and people skill is important. Thus, as an alternative to it, we have put forward the idea of earth block construction which is not only earthquake resillient but lighter, greener sustainable and economical.
\end{abstract}

Keywords: Nepal, Gorkha Earthquake, Building Types, Earth construction, Sustainability

\section{Introduction}

Nepal lies in the center of Himalayan mountain chain, which is one of the most active seismic regions in the world due to the faulting between the sub ducting Indian Plate and the overriding Eurasian plate as shown in Fig. 1.

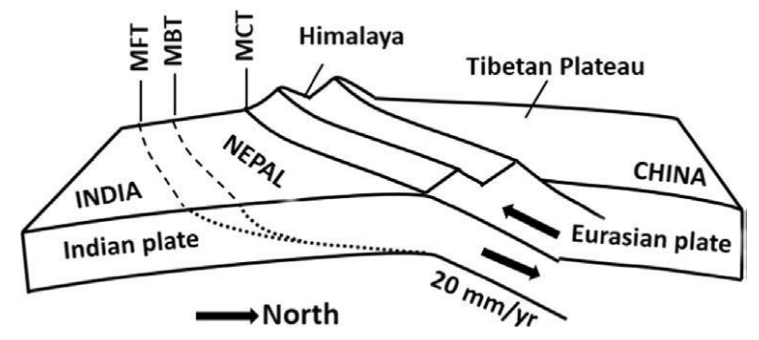

Fig. 1: Type of plate boundaries in Nepal (Primary surface ruptures of the great Himalayan earthquakes in 1934 and 1255) [2] 
The Indian plate overrides the Eurasian plate every year by almost $45 \mathrm{~mm}$ towards the northnortheast and as warned by the researchers, Nepal was vulnerable to earthquake from a long time due to its geology [1]. On April 25, 2015, a strong earthquake of M 7.8 struck central Nepal resulting in the loss of 8790 lives and 22300 injuries[9]. Another major aftershock of M 7.3 struck on May 12, 2015. The earthquake resulted in the damage of 500000 buildings, 4000 government offices and 8200 school buildings [6].

According to the data from World Bank, 81 percent of the people in Nepal live in rural areas and $44.2 \%$ percent of buildings in Nepal are masonry type buildings which are mostly located in the rural areas of Nepal [13]. Most of these places aren't well connected with transportation facilities. These have led to the high price of materials in these areas. People living in rural areas have lower income and are not able to afford the building materials like cement, steel, fired bricks etc. which is transported to the rural from urban areas. There is very less skilled manpower in these areas. With insufficient skilled manpower and use of natural resources locally available to build houses have led to the poor performance of buildings in these areas. These have been reflected in the recent 2015 Nepal Earthquake where the masonry type buildings performed the worst. Thus, there is a need of earth construction with the use of natural resources which is earthquake resistance, greener and economical.

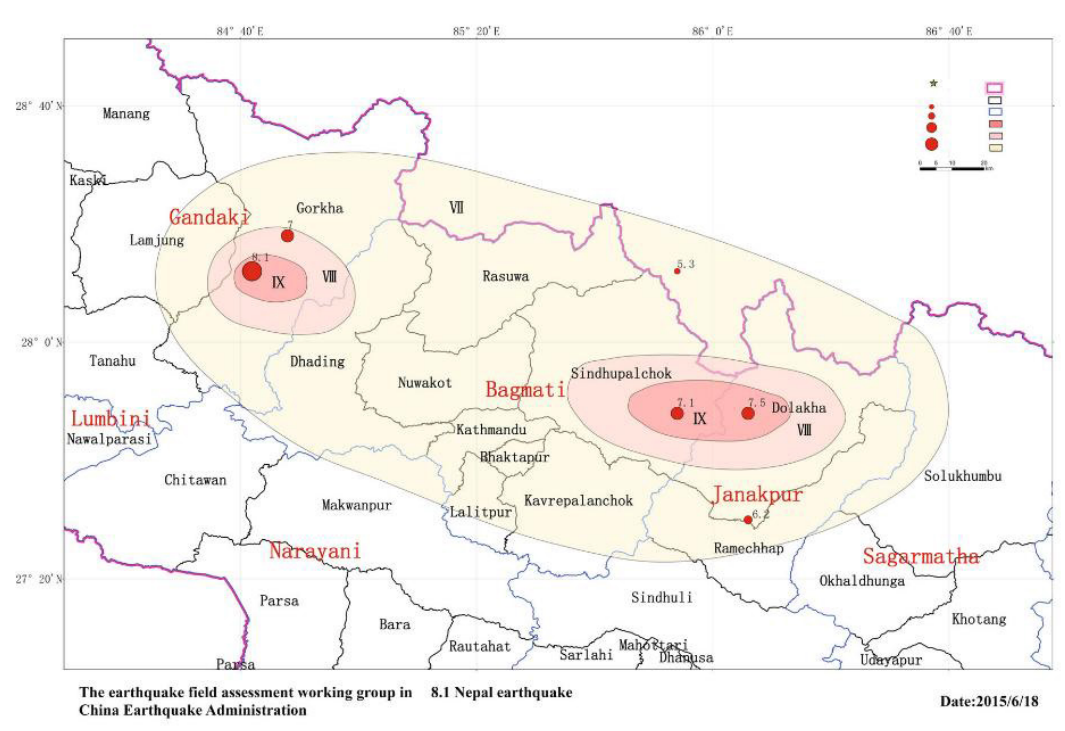

Fig. 2: Seismic intensity map of Nepal earthquake [10]

$\mathrm{RC}$ buildings are generally found in the urban areas of the country. The performance of RC building was hampered due to the low strength of concrete, non-seismic detailing of beam column joints, poor construction quality and so on. The performance of Brick/Stone Masonry was the worst during the earthquake. This was mainly due to the use of poor quality of bricks and mortars and lack in construction detailing. A general introduction to the building types of Nepal and the extent of damage due to the earthquake have been presented in this paper. As masonry type building is mostly found in Nepal, the poor performance of it in the earthquake has given us 
various lessons and alternatives. One of the main factor is the performance of brick used in the brick masonry buildings. Thus, the main idea of the paper is to relate to the use of earth blocks in buildings mainly in the rural areas which is not only earthquake resistance but also green and economic with respect to the economic condition of Nepal.

\section{Building Types in Nepal}

Generally, the materials used in traditional buildings are mud, bamboo, brick, stones, straw, iron etc. These materials have been used from hundred years ago as it was an easily available resource for construction in Nepal. As one third of the country is covered with forest, timber was widely used in different parts of building such as roofs, doors, windows, beams and columns[11]. Brick and clay mortar is also popular in Nepal . The concrete has been slowly replacing the modern buildings mostly in the urban areas of the country. Bricks, concrete and steel is now widely used. The 1988 earthquake in Nepal resulted in the establishment of Nepal Building Code (NBC) which was formulated in 1994 [8]. NBC mostly deals with the strength of buildings. The main idea is to improve the seismic capacity of the existing buildings and plan for design and construction that is safe. Till date, the implementation of the code has been the biggest challenge. It has been circulated to 130 municipalities in Nepal, however, only 3 municipalities have done a bit in adopting the building code namely; Kathmandu, Lalitpur and Dharan . The VDC (Village Development Committee) still have no regulations.

The population of Nepal is 26,494,504 and the number of individual households is 5,423,297 as per the Nepal Census 2011 [4]. As per the data from Nepal Census 2011, 44.2\% of the total buildings consists of brick/stone masonry with mud mortar (BM/SM). The wooden buildings (W) comprises $24.9 \%$ of the total buildings whereas Cement bounded brick/stone (BC/SC) consists of $17.6 \%$. Only $9.9 \%$ of the total buildings are cement concrete (RCC). Remaining 3 percent (A) represents as non-categorised buildings. The summarized detail is given in Fig. 3.

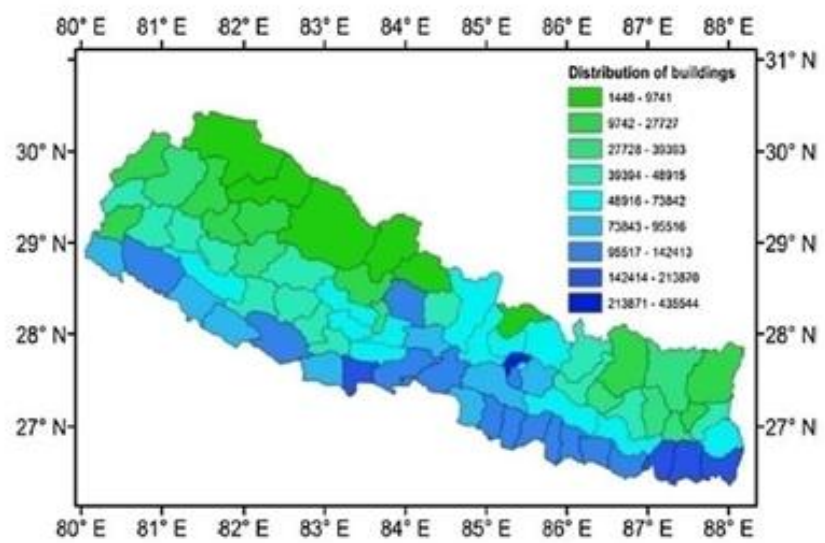

a) District wise distribution of buildings

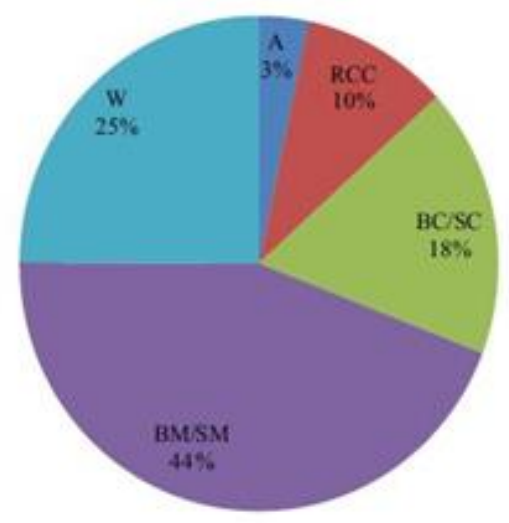

b) Building Types in Nepal (CBS 2012)

Fig. 3: District wise distribution of buildings and the types of buildings in Nepal [5] 
The average height of buildings in Nepal is about 2.5 to 3.2 meters with wall thickness varying from $230 \mathrm{~mm}$ to $300 \mathrm{~mm}$. The traditional brick masonry buildings are generally 1 to 5 floors high. The brick masonry is generally found in the plain areas and where the road is easily accessible. The walls of these buildings are constructed using fired bricks or fired and sun dried bricks as shown in Fig. 4. The traditional brick masonry buildings are described by its heavy mass. It possesses very low strength and show brittle nature for failure resulting in sudden collapse of building during earthquake. However, the performance is better compared to stone masonry. Modern brick masonry are up to 6 floors high, uses cement sand mortar and are less vulnerable compared to traditional ones although most of the modern are still non-engineered.

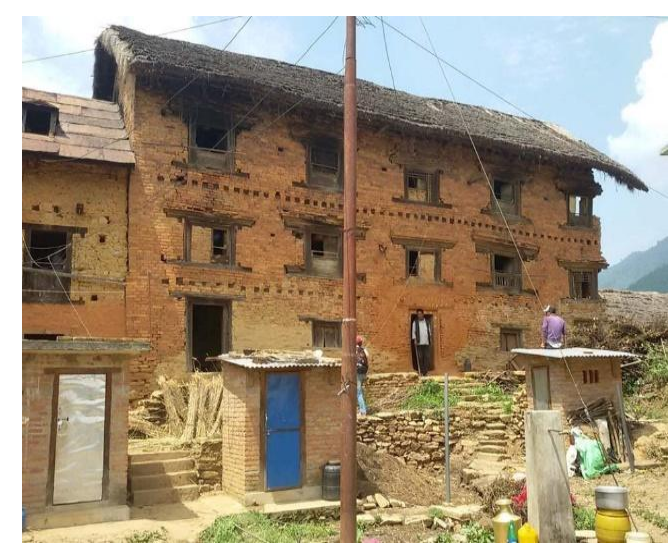

Fig. 4: Brick Masonry with mud mortar [14]

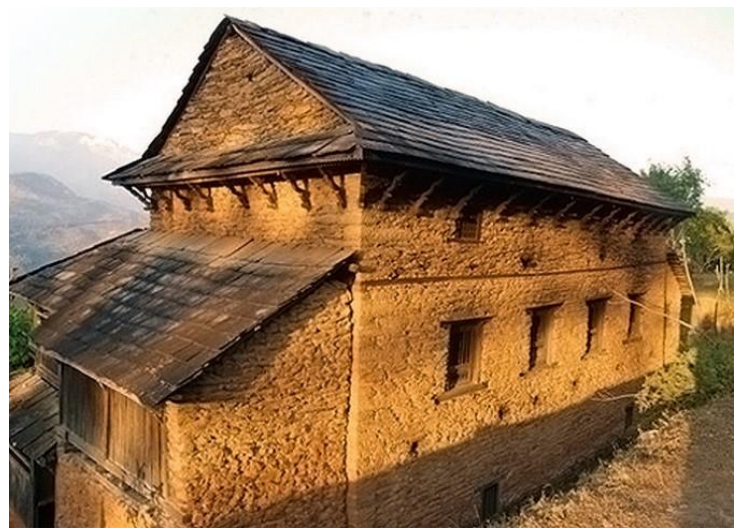

Fig. 5: Typical Stone Masonry with mudmortar[12]

The stone masonry buildings are mostly found in the northern mountainous region of Nepal. It is popular due to the ease of availability of construction materials. It is one of the affordable and cost effective construction. Seismic forces are ignored in this type of building. It is characterized by its heavy mass, low strength and brittle nature of failure (Fig. 5). These buildings are generally build by the owners or local builders. Modern stone masonry building uses cement sand mortar.
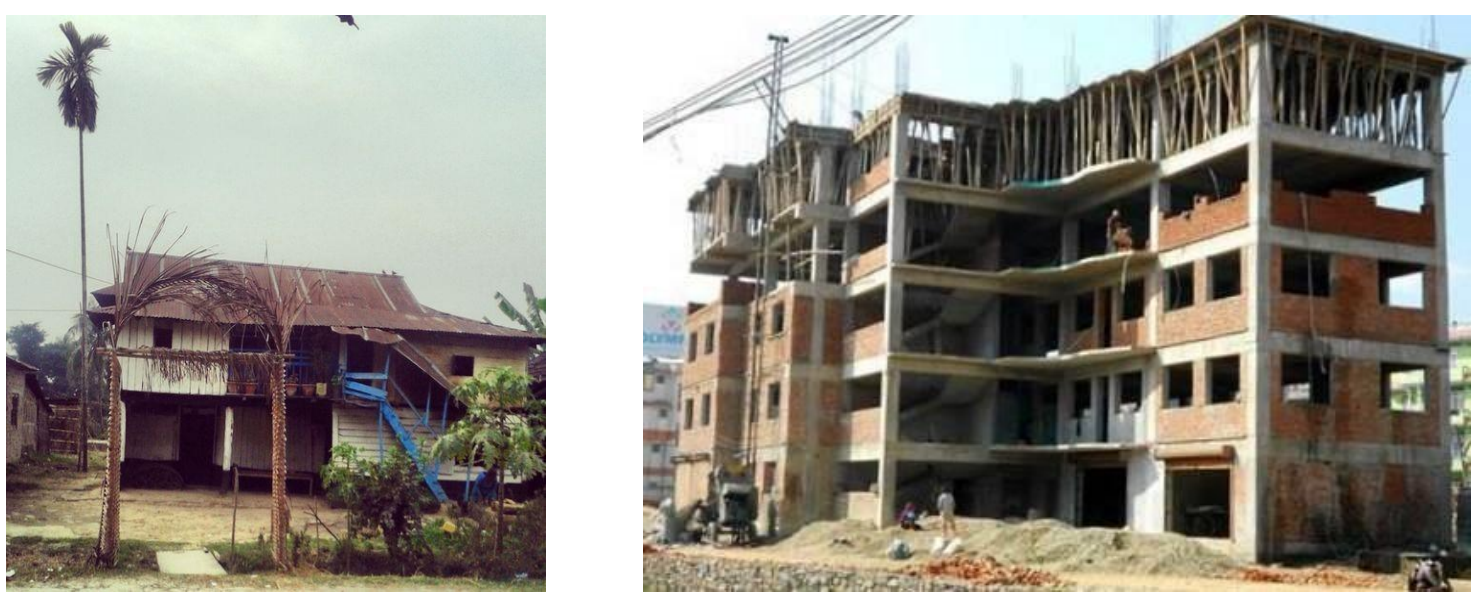

Fig. 6: Wooden Building[15]

Fig. 7: RCC building under construction in Kathmandu, Nepal [3] 
The Wooden buildings are commonly used in major cities of Kathmandu, Patan and Bhaktapur (Traditional wooden buildings) and in the rural areas. These are used for both religious and residential buildings in old downtowns. A typical wooden building is shown in Fig. 6. The RCC building is widely used in the developed region of Nepal. It is popular among the wealthy families. These buildings are mostly common in government offices, hospitals, schools, hotels etc. Most of the buildings haven't followed the seismic design code except for government and public buildings. The RC buildings are generally 3 to 5 stories high as Nepal does not have much high rise buildings. A RCC building with infill walls under construction is shown in Fig. 7.

\section{Earthquake Performance of Buildings}

The recent earthquake in Nepal on $25^{\text {th }}$ April 2015 has drawn much international attention due to the damage of buildings and loss of human lives. The Brick/Stone Masonry buildings performed the worst compared to other types of buildings (Fig. 9). The main reason was the use of poor quality of mortar and bricks that were unable to bear the deformation during earthquake. This has led to high casualty. The quality of bricks and stones matters in every step of bonding process. The size of bricks used was found to be inconsistent and the crushing strength less than the specified, i.e. less than $3.5 \mathrm{~N} / \mathrm{mm} 2$ as prescribed by the National Building Code (NBC 205 : 1994). $240 * 115 * 57 \mathrm{~mm}$ standard size of brick is preferred. The heavy weight of the building has also led to greater extent of damage.
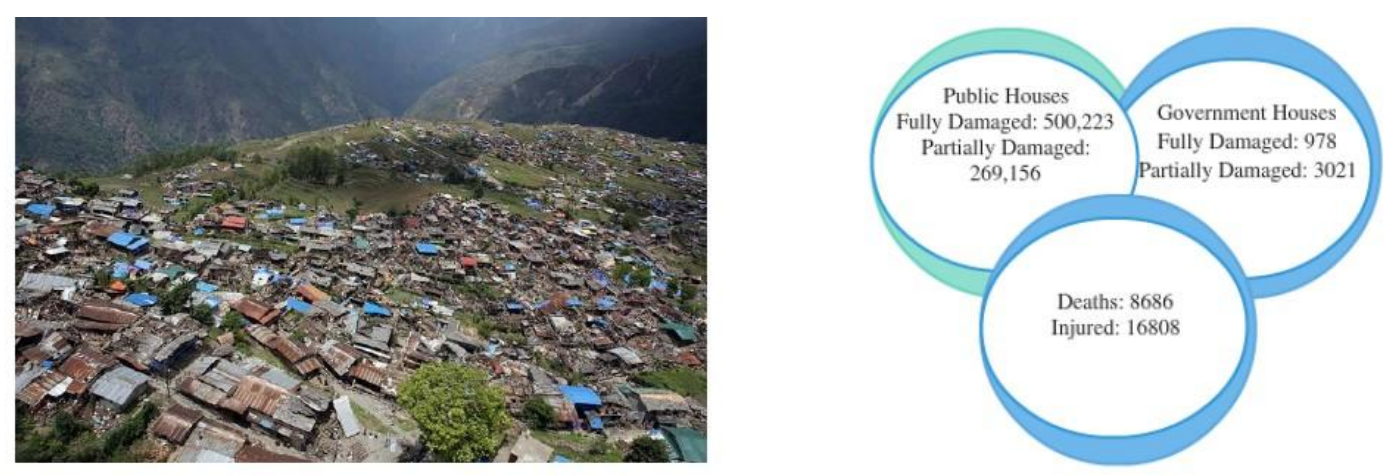

Fig. 8: Human and Property Loss by Gorkha Earthquake, 2015 (Source: USAID, 2015) 


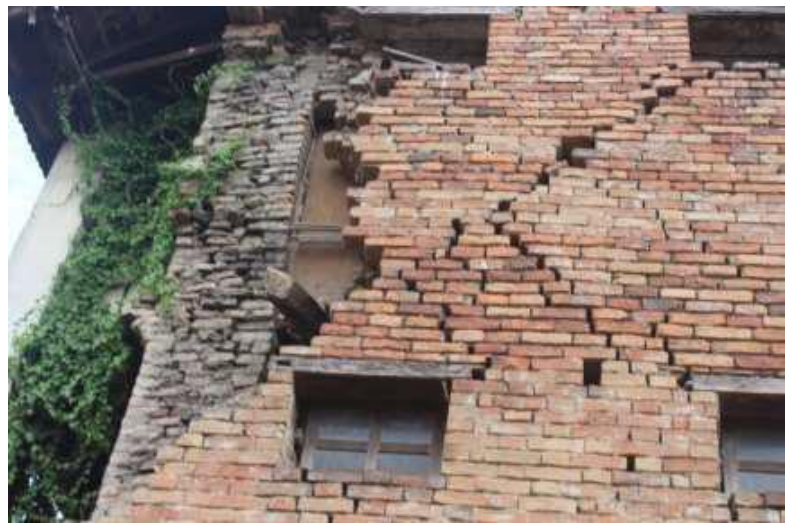

Fig. 9: (a) Binding Material Failure[15]

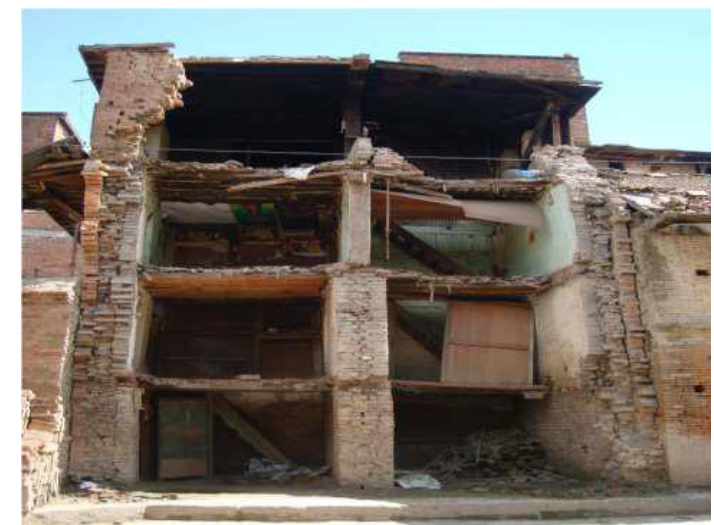

(b) Out of plane failure [15]

Table 1: Damage Scenario (NPC, 2015) [3]

\begin{tabular}{|l|l|l|l|}
\hline Damage Share & Low Strength Masonry & Cement Masonry & RC Based \\
\hline Complete & $474025(95 \%)$ & $18214(3.7 \%)$ & $6613(1.7 \%)$ \\
\hline Partial & $173867(67.7 \%)$ & $65859(25.6 \%)$ & $16971(6.7 \%)$ \\
\hline
\end{tabular}

The damage in wooden frame buildings has been due to slope failures and large ground movements during earthquake. Cracking and collapse of brick veneer on building exterior can been seen (Fig. 10).
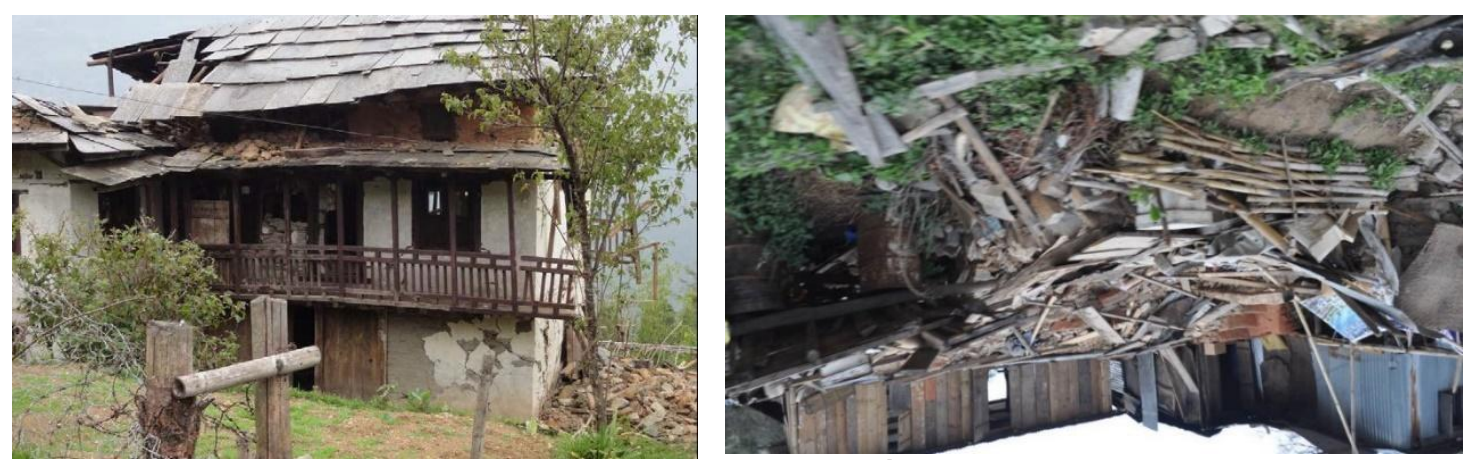

Fig. 10: Wooden buildings after Earthquake on $25^{\text {th }}$ April 2015 (Source: EERI) [7]

The RC buildings are generally found in the urban areas of Nepal. The recent earthquake has affected the RC buildings too. In Nepal, generally burnt clay bricks or stones are used as the wall filling materials. There is absence of RC or masonry bond above doors and windows. Failure of beam column joints has been seen in many RC buildings as a result of the earthquake (Fig. 11). Weak detailing at the beam column joint, widely spaced stirrups i.e. spacing of stirrups is larger than specified by Nepal National Building Code are some of the causes of failures. Short column failures have been due to intermediate staircase landing between 2 floors and for requirements as ventilation. Short columns are generally vulnerable to earthquakes. Poor detailing, poor quality of concrete are some other reasons for failure. 

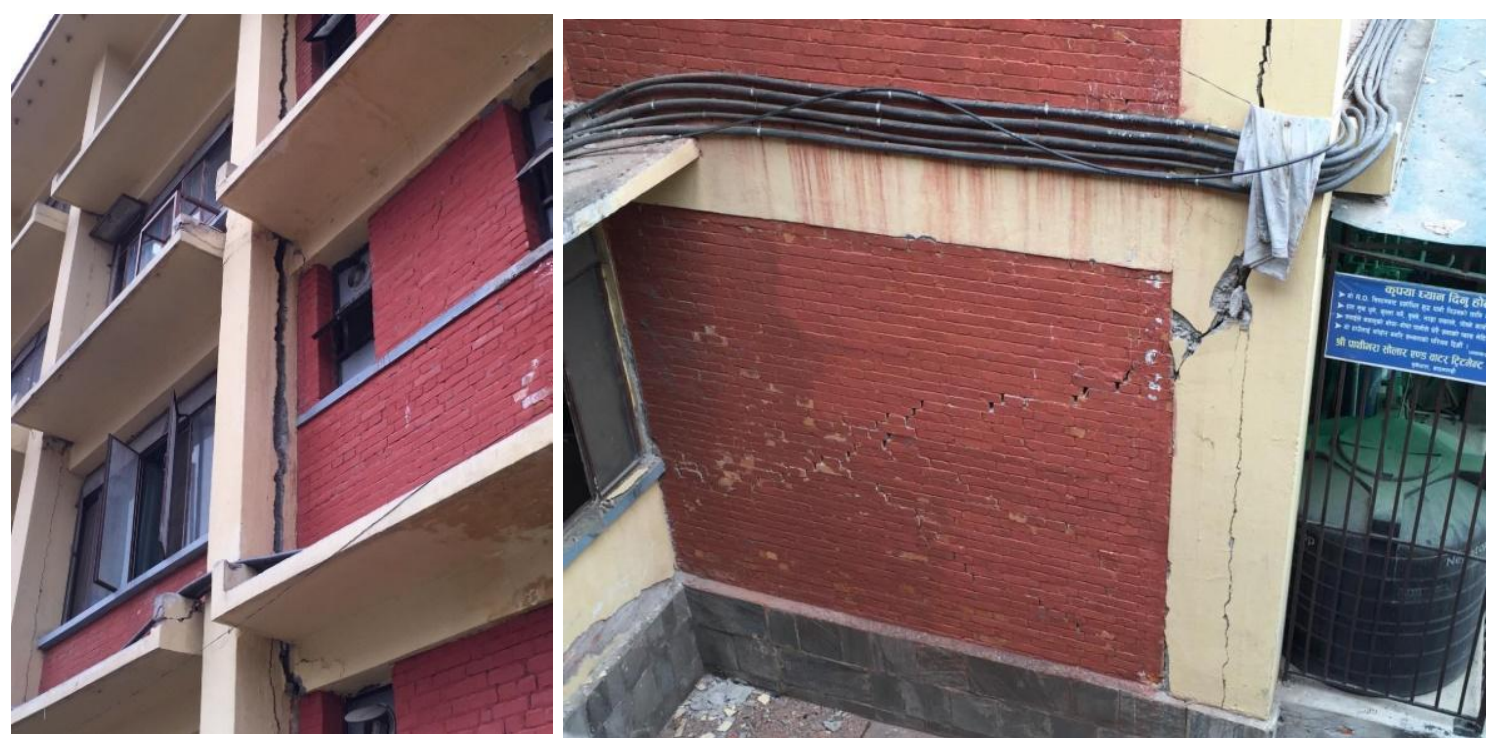

Fig. 11: Failure of Column Joints during April 2015 Earthquake (Source : EERI) [7]

\section{Earth Construction}

Earth Construction is one of the oldest and most cost effective method of construction. It can be found in many parts of the world including Africa, Europe, North America, South America, Middle East Asia to name few. The earth construction has numerous advantages of which the utilization of the locally available resources is the most significant. This reduces the transportation cost and make the houses much cheaper and affordable to the people. It increases the economic growth and generates local jobs eliminating the need of skilled manpower. It is an easier and faster method of construction. As the earth blocks are renewable, it is environment friendly. Moreover, they are cooler in summer and warmer in winter. The houses built with earth blocks require less energy for heating and cooling. Thus, it reduces the energy consumption leading to less environment pollution and saves money too. Earth Construction buildings take much lesser time to build compared to the normal ones. The construction is also simplified due to the uniformity of the bricks. The blocks are non-toxic as the materials are completely natural. The blocks are fire, water resistance too. One of the main disadvantage of earth blocks is that the composition of soil may not be appropriate and sometimes may need to be transported to places. The composition may also hamper the overall properties of the block. Thus, the study of soil properties in a place is very important.

44.2\% percent of buildings in Nepal are masonry type buildings which are mostly located in the rural areas of Nepal. Most of these places aren't well connected with transportation facilities. These have also led to the high price of materials in these areas. Most of the people in these areas have low income and cannot afford the building materials like cement, steel, fired bricks etc. which is transported to the rural from urban areas. They are compelled to use the natural resources available in the area. There is very less skilled manpower in these areas. With insufficient skilled manpower and use of natural resources locally available to build houses have led to the poor performance of buildings in these areas. These have been reflected in the recent 
2015 Nepal Earthquake where the masonry type buildings performed the worst. Thus, our idea is to build a house with earth construction using the locally available soil in the area. These don't need skilled manpower as used in the concrete and steel houses. This will in fact create more job opportunities and increase the economic activity of the area. The houses constructed with earth blocks have high seismic resistance. Moreover, these earth constructions are green and have a very high insulating properties. This will make housing affordable among the rural people with one of the best safety standard.

\section{New Innovative Earth Block}

Based the objective of ease of construction and placing mortarless, and the dimensions of brick used in Nepal, we have designed a new type of earth brick. It consists of two types of block: (a) a complete block (b) a half block as shown in Fig. 12.

The block has holes and grooves but not protrusions as shown in Fig. 12. The protrusions in the block account to the difficulty in processing and hence not provided. The blocks have a dimension of $360 \mathrm{~mm} \times 180 \mathrm{~mm} \times 90 \mathrm{~mm}$ and $180 \mathrm{~mm} \times 180 \mathrm{~mm} \times 90 \mathrm{~mm}$ for a full block and half block respectively. The dimension of the block is considered according to the brick sizes used in Nepal. The arrangement of blocks is shown in Fig. 13.

As there is no self-locking mechanism due to the elimination of protrusions, the process of aligning the blocks are much easier. The masonry can be set up with the vertical reinforcements passing through the holes and can be completed with the pouring of the grout through the holes which can efficiently increase the shear strength and the overall performance of the wall. The presence of steel helps in the improvement of the ductility of the wall. There are holes provided in the bricks which is much larger at the contact surface. This helps the grouting material at that section to be larger which can increase the bearing capacity and reduce the stress concentration at the blockhole caused by shearing. The arrangement of the bricks at T-section and corner is shown in Fig. 14 and Fig. 15 respecively.

In comparison to the other interlocking earth blocks, the main advantages of this system is as follows:

(1) Self-alignment with ease of construction

(2) As there is no keyway structure, the accuracy of the production process is reduced, hence, easier for the production process. Also, stacking, transportation is much easier. The bricks are also less likely to be damaged due to the collision.

(3) The grouting through the holes of the bricks which connects to make the wall as a whole, reducing the block local defects cause by stress concentration, can make the connection between the blocks more rigid. 
72 Earth Block Construction in Nepal as Alternative to Reconstruction after the 2015 Gorkha Earthquake
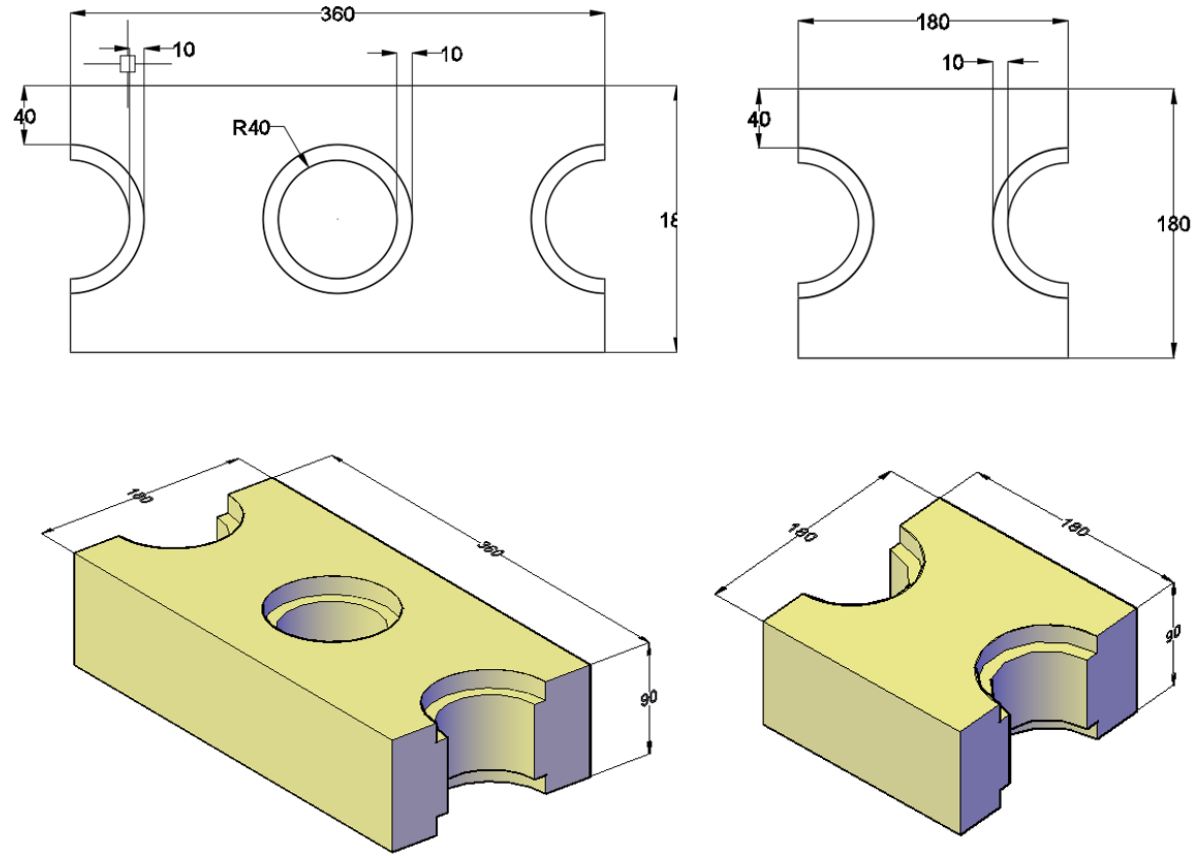

Fig. 12: Full Block and Half Block

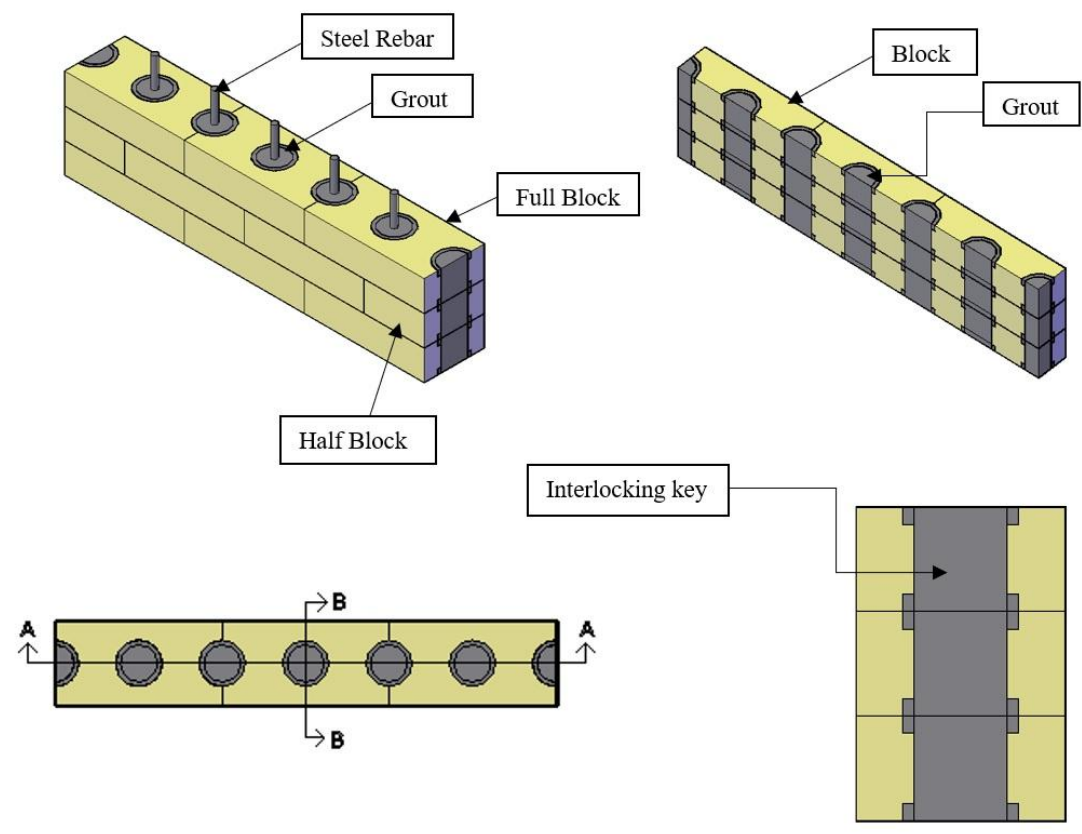

Fig. 13: Embed pattern of Blocks 


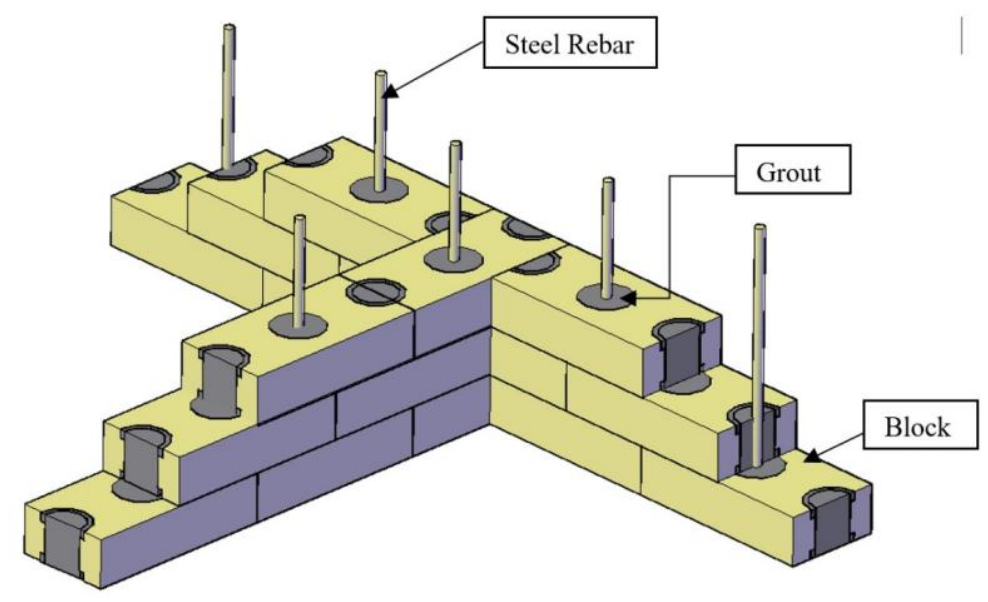

Fig. 14: Block arrangement at T-section

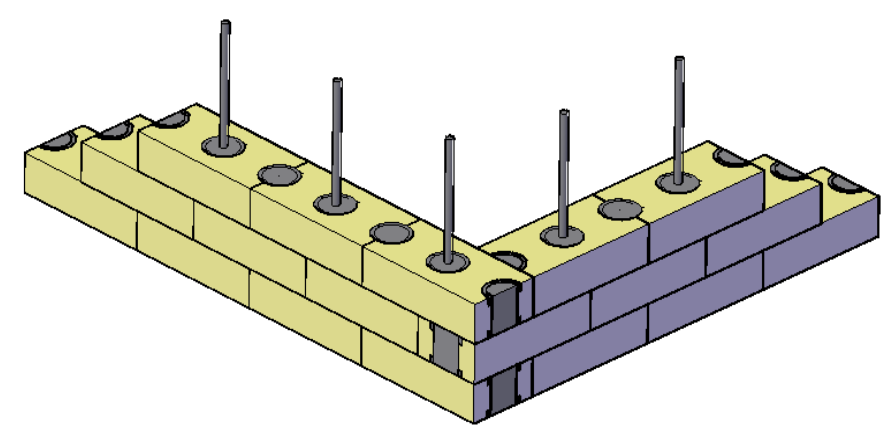

Fig. 15: Block arrangement at the corner

\section{Conclusion}

The April 2015 earthquake caused massive loss to the country and its people. There is a lot to learn from it so that we can overcome these situations shortly. One of the main reason for the poor performance of the buildings was the use of poor brick and mortar that could not resist the earthquake. The RC buildings are concentrated in the urban areas, and the masonry buildings are in the rural areas. These rural areas lack resources, skilled workforce and the implementation of the only available local resources, have compromised the design configuration of buildings which is a significant threat to future earthquakes. Moreover, due to the economic condition of people, they opt for cheaper construction by overseeing the seismic configuration. The rural areas of Nepal have not been well connected with transportation facilities due to which people are compelled to pay higher prices for construction materials. Many people living in rural areas have a low income and cannot afford it. Earth blocks are cheaper as the soil is readily available in 
many parts of the country and mostly the local resources are used in it. For a country like Nepal, where the transportation to the rural areas of the country is not well connected, this new earth block will help eradicate these issues. Thus, this earth blocks can be made on site with the use of natural resources and is most suitable for Nepal which is light, green, economical and most importantly can resist the seismic forces.

\section{References}

[1] Alam AK and Ahsan A (2015), On Bangladesh Experience from the 25 April 2015, Nepal Earthquake.

[2] Bettinelli P, Avouac J, Flouzat M, Jouanne F, Bollinger L, Willis P and Chitrakar GR (2006), Plate motion of India and interseismic strain in the Nepal Himalaya from GPS and DORIS measurements. Journal of Geodesy, 80(8) : 567-589.

[3] Brzev S, Scawthorn C, Charleson AW, Allen L, Greene M, Jaiswal K and Silva V (2013), GEM Building Taxonomy (Version 2.0) (No. 2013-02). GEM Foundation.

[4] CBoS, N (2012), National Population and Housing Census 2011, National Report.

[5] Chaulagain H, Rodrigues H, Silva V, Spacone E and Varum H (2015), Seismic risk assessment and hazard mapping in Nepal. Natural Hazards, 78(1) : 583-602.

[6] Gautam D, Bhetwal KK, Rodrigues H, Neupane P and Sanada Y (2015), Observed damage patterns on buildings during 2015 Gorkha (Nepal) earthquake. In Proceedings of $14^{\text {th }}$ international symposium on new technologies for urban safety of mega cities in Asia (pp. 29$31)$.

[7] Kaushik H, Bevington J, Jaiswal K, Lizundia B and Shrestha S (2016), Buildings (EERI Earthquake Reconnaissance Team Report: M7. 8 Gorkha, Nepal Earthquake on April 25, 2015 and its Aftershocks) (pp. 5-1). Earthquake Engineering Research Institute

[8] Nepal Building Code (1994), Retrieved from. http://www.dudbc.giv.np/buildingcode

[9] NPC (2015), Nepal Earthquake 2015: Post Disaster Needs Assessment, Government of Nepal, National Planning Comission, http://www.npc.gov.np/images/category/PDNA_volume_BFinalVersion.pdf

[10] Sun B and Yan P (2015), Damage characteristics and seismic capacity of buildings during Nepal Ms 8.1 earthquake. Earthquake Engineering and Engineering Vibration, 14(3) : 571578.

[11] The World Bank. Forest area (\% of land area). Retrieved from https://data.worldbank.org/indicator/AG.LND.FRST.ZA

[12] The World Bank. Rebuilding Nepal with Traditional Techniques. http://blogs.worldbank.org/endpovertyinsouthasia/rebuilding-nepal-traditional-techniques

[13] The World Bank. Rural Population. Retrieved from http://data.worldbank.org/indicator/SP.RUR.TOTL.ZS

[14] Traditional Buildings Inventory. Retrieved from https://www.facebook.com/TraditionalBuildings-Inventory-TBI-NEPAL-667680163375872/

[15] Traditional House in terai Region, https://www.pinterest.com/pin/259942209717911642 (accessed Dec 2017). 